\title{
Comparing the ecological impacts of native and invasive crayfish: could native species' translocation do more harm than good?
}

\author{
J. James $\cdot$ F. M. Slater $\cdot$ I. P. Vaughan $\cdot$ K. A. Young $\cdot$ \\ J. Cable
}

Received: 4 April 2014 / Accepted: 12 December 2014

(C) Springer-Verlag Berlin Heidelberg 2014

\begin{abstract}
Biological invasions are a principal threat to global biodiversity. Omnivores, such as crayfish, are among the most important groups of invaders. Their introduction often results in biodiversity loss, particularly of their native counterparts. Managed relocations of native crayfish from areas under threat from invasive crayfish into isolated 'ark sites' are sometimes suggested as a conservation strategy for native crayfish; however, such relocations may have unintended detrimental consequences for the recipient ecosystem. Despite this, there have been few attempts to quantify the relative impacts of native and invasive crayfish on aquatic ecosystems. To address this deficiency we conducted a meta-analysis on the effects of native and invasive crayfish on nine ecosystem components: decomposition rate, primary productivity, plant biomass, invertebrate density, biomass and diversity, fish biomass and refuge use, and amphibian larval survival. Native and invasive crayfish significantly reduced invertebrate density and biomass, fish biomass and amphibian survival rate and significantly increased decomposition rates. Invasive crayfish also significantly reduced plant biomass and invertebrate diversity and increased primary productivity. These results show that
\end{abstract}

Communicated by Barbara J. Downes.

Electronic supplementary material The online version of this article (doi:10.1007/s00442-014-3195-0) contains supplementary material, which is available to authorized users.

J. James $(\varangle) \cdot$ F. M. Slater · I. P. Vaughan · J. Cable

School of Biosciences, Cardiff University, Cardiff CF10 3AX,

UK

e-mail: jamesj12@cf.ac.uk

K. A. Young

Institute of Biological, Environmental and Rural Sciences

(IBERS), Aberystwyth University, Aberystwyth SY23 3DA, UK native and invasive crayfish have wide-ranging impacts on aquatic ecosystems that may be exacerbated for invasive species. Subsequent analysis showed that the impacts of invasive crayfish were significantly greater, in comparison to native crayfish, for decomposition and primary productivity but not invertebrate density, biomass and diversity. Overall, our findings reconfirm the ecosystem altering abilities of both native and invasive crayfish, enforcing the need to carefully regulate managed relocations of native species as well as to develop control programs for invasives.

Keywords Invasive species - Managed relocations · Meta-analysis $\cdot$ Keystone species $\cdot$ Ecosystem engineers

\section{Introduction}

Invasive species are considered to be the second greatest threat to global biodiversity following habitat loss (Didham et al. 2005; Gurevitch and Padilla 2004). Worldwide, invasive species have been identified as a contributing factor in the extinction of 91 species, 34 of which are thought to have become extinct exclusively as a result of biological invasions (Clavero and García-Berthou 2005). The effects of species invasions may be particularly severe in freshwaters, which represent some of the most biodiverse ecosystems (Dudgeon et al. 2006; Strayer and Dudgeon 2010). Within freshwater ecosystems powerful omnivores, such as crayfish, are regarded as among the most ecologically important groups of biological invaders (Strayer 2010). At least 28 species of crayfish are established outside of their native range, and seven are considered to be invasive (Gherardi 2010). Most notably, American species including signal crayfish (Pacifastacus leniusculus) and red swamp crayfish (Procambarus clarkii) have been widely 
introduced across Europe, where impacts upon aquatic flora and fauna have been extensively documented (e.g. Unestam and Weiss 1970; Nyström et al. 2001; Stenroth and Nyström 2003; Bubb et al. 2006; Olden et al. 2006; Bubb et al. 2009; Axelsson et al. 1997).

One of the most notable impacts of invasive crayfish is to drive declines amongst their native counterparts due to competition and/or disease transmission (e.g. Unestam and Weiss 1970; Bubb et al. 2006; Olden et al. 2006). To counter such declines, managed relocations of native crayfish within and outside their natural ranges are often suggested (Olden et al. 2010). Such relocations typically target naturally or artificially isolated water bodies to create 'ark' populations protected from range expansion by invasive species (Haddaway et al. 2012). Relocations have been conducted in parts of the UK to conserve native white clawed crayfish (Austropotamobius pallipes), which have declined rapidly in range and abundance since the introduction of invasive signal crayfish in the 1970s (Sibley et al. 2002; Haddaway et al. 2012). Such relocations of native species outside of their home range raises the controversial issue of whether these new populations should be regarded as invasive and hence viewed as a potential threat to the recipient ecosystem (Olden et al. 2010). Regardless of this, native crayfish display similar polytrophic feeding behaviours to invasive crayfish and so possess the ability to alter the structure and function of the ecosystem into which they are introduced. Risk assessments, however, for managed translocations are sometimes ignored in favour of the potential conservation benefits of such actions.

Evaluating the potential detrimental impacts of managed translocations of native crayfish populations is challenging as there is a strong bias in the crayfish literature toward studies on invasive crayfish species. A recent meta-analysis on the impacts of crayfish on aquatic ecosystems found that invasive crayfish reduced the abundance and/or biomass of aquatic macrophytes and invertebrates and reduced the abundance and/or growth rate of fish and amphibians but did not consistently affect algal biomass (Twardochleb et al. 2013). The impacts of native crayfish were, however, only considered in relation to those of non-native species (Twardochleb et al. 2013). Overall, invasive crayfish caused greater reductions in invertebrate and fish biomass and abundance and greater increases in algal biomass than native crayfish; however, results were variable and comparisons were only made between specific non-native-native crayfish species pairs (Twardochleb et al. 2013). With the demand for population relocations of native crayfish predicted to increase with intensified pressure from invasive crayfish species it is essential to collate and synthesise all available data on the ecological impacts of native species. Such a meta-analysis will allow the benefits of native species' conservation through population translocation to be weighed against the potential risks to wider communities (Olden et al. 2010).

Here, we conduct a global meta-analysis of the published literature concerning the impacts of native and invasive crayfish on a range of taxa and ecosystem processes. We provide a quantitative synthesis of the impacts of crayfish on aquatic ecosystems through testing the following hypotheses relevant to native crayfish managed relocation planning and invasive species risk assessment:

1. Native and invasive crayfish perform similar functional roles, i.e. impact the same aquatic taxa and ecosystem process.

2. The magnitude of the impact of crayfish on individual aquatic taxa and/or ecosystem process will be greater for invasive than native crayfish.

3. The impacts of crayfish on aquatic organisms and/or ecosystems processes will increase with crayfish density.

\section{Materials and methods}

\section{Study selection and data extraction}

We used keyword searching in Web of Knowledge and Google Scholar to identify peer-reviewed papers quantifying the effects of crayfish on aquatic ecosystems. We also examined reference lists for additional papers, and in some cases contacted authors to gain data that were otherwise unavailable. Literature searches were conducted in 2012. All study types (i.e. laboratory experiments, field mesocosm experiments, field observational studies) and both still and running waters were considered. We examined 132 papers, 44 of which contained relevant studies and reported the following information necessary for inclusion in our meta-analysis: the mean and either SDs, SEs or $95 \%$ confidence intervals (CIs) of the aquatic organism/ecosystem process in the presence (treatment group) and absence (control group) of crayfish, the sample sizes of each of these groups, and native/invasive status of the crayfish species at the study location (here forth referred to as 'crayfish status'). Of these 44 papers only 35 were used in the meta-analysis (Online Resource 1) as we excluded aquatic organisms/ecosystem processes for which fewer than three independent studies were available. Means and SDs/SEs/ CIs were measured directly from figures, through enlarging them and manually calculating values with a ruler if they were not presented within the text or as tables. When reported, information on study duration and density of crayfish was also included, but this information was not mandatory for inclusion in the meta-analysis. The same paper could provide multiple observations for the meta-analysis 
if independent experiments were conducted using different crayfish species and/or a single experiment measured the effect of crayfish on multiple ecosystem components.

The meta-analysis included the following taxa or ecosystem processes:

1. Decomposition rate of dried terrestrial leaf packs (measured as percentage of leaf biomass remaining at the end of the study).

2. Primary productivity (measured as chlorophyll $a$ production and/or periphyton abundance).

3. The standing crop of macrophytes (referred to as plant biomass).

4. The density or biomass (analysed independently) of benthic macro-invertebrates other than crayfish.

5. Macro-invertebrate diversity.

6. The biomass and refuge use of fish (measured as the number of fish per shelter).

7. Survival rate of amphibian eggs and/or larvae (measured as the percentage of eggs and/or larvae remaining at the end of the experiment).

To avoid pseudo-replication in the principal meta-analysis we applied the following rules (McCarthy et al. 2006): when response variables were measured at multiple time points, only the final observation was used; when experiments included crayfish sex as a factor, data for male crayfish were used (to maximize total sample size as for 61 of the 93 effect sizes $(d)$ calculated from experimental studies only male crayfish were used); when several crayfish densities were studied, we used data from the highest density treatment. However, data for all density treatments were collected and included in a complementary analysis testing whether $d$ differed with crayfish density. Additional analyses including crayfish sex as a variable were not conducted, as separate data for female crayfish were only available for four out of the $93 d$ calculated from experimental studies. For the majority of $d$ (66 out of 93) calculated from experimental studies the crayfish used were adults. Of the remaining $27 d$, four were calculated from studies using only juvenile crayfish and the rest from those using crayfish of mixed or indeterminate life stages.

\section{Calculations of $d$}

Following Gurevitch and Hedges (2001), for each observation the $d$ was calculated as:

$d=\frac{X_{\mathrm{t}}-X_{\mathrm{c}}}{\mathrm{SD}_{\text {pool }}} J$

where $X_{\mathrm{t}}$ and $X_{\mathrm{c}}$ are the mean values for the treatment and control groups, respectively, and $\mathrm{SD}_{\text {pool }}$ is the pooled $\mathrm{SD}$, calculated as:
$\mathrm{SD}_{\text {pool }}=\sqrt{\frac{\left(N_{\mathrm{t}}-1\right)\left(\mathrm{SD}_{\mathrm{t}}\right)^{2}+\left(N_{\mathrm{c}}-1\right)\left(\mathrm{SD}_{\mathrm{c}}\right)^{2}}{N_{\mathrm{t}}+N_{\mathrm{c}}-2}}$

where $N_{\mathrm{t}}$ and $N_{\mathrm{c}}$ are the numbers of replicates, and $\mathrm{SD}_{\mathrm{t}}$ and $\mathrm{SD}_{\mathrm{c}}$ the SDs, for the treatment and control groups, respectively. In Eq. $1 J$ corrects for small sample sizes and was calculated as:

$J=1-\frac{3}{4\left(N_{\mathrm{t}}+N_{\mathrm{c}}-2\right)-1}$

Statistical analysis

For each $d$, we calculated the variance in the $d$ estimate, $v$, as:

$v=\left(\frac{N_{\mathrm{t}}+N_{\mathrm{c}}}{N_{\mathrm{t}} N_{\mathrm{c}}}+\frac{d^{2}}{2\left(N_{\mathrm{t}}+N_{\mathrm{c}}\right)}\right)$

From $d$ a weighted mean effect size of the $i$ observations was calculated for each ecosystem component as:

$d^{+}=\frac{\sum_{i} w_{i} d}{\sum_{i} w_{i}}$

where each $d$ observation is weighted by $w$, the reciprocal of the sampling variance, $v$ (see Eq. 4 ), and the variance of $d^{+}, v^{+}$is calculated as:

$v^{+}=\frac{1}{\sum_{i} w_{i}}$

For each ecosystem component we calculated the $95 \%$ CI of $d^{+}$as: $d^{+} \pm\left(1.96 \sqrt{ } \mathrm{v}^{+}\right)$. This procedure allows the CI to be calculated for weighted mean $d$ of a single study $[n=1$ (Gurevitch and Hedges 2001)]. Weighted mean $d$ ( $\pm 95 \%$ CI) were calculated separately for native and invasive crayfish and determined as significant if these CIs did not intercept zero.

To test for publication bias across $d$ normal quantile plots of standardized $d$ were generated using MetaWin meta-analytical software. Forest plots of individual $d$ were created for each ecosystem component with studies grouped depending on whether the crayfish used in them was native or invasive to the study region (Online Resource 2).

Linear models were used to investigate factors influencing $d$. The first model focused upon decomposition rate and primary productivity, whilst the second analysed invertebrate density, biomass and diversity. These categories had larger samples sizes ( $n \geq 5$ studies) and were primarily mesocosm studies (cf. laboratory based studies for amphibians). Grouping the two ecosystem processes together, and the three invertebrate metrics, maximised the power of the two analyses, rather than analysing them individually. The full models regressed $d$ upon ecosystem component, crayfish endemic status (native or invasive), crayfish density, 
Table 1 Summary of all papers on native and invasive crayfish used in the current metaanalysis (N.B. some papers include studies on multiple crayfish species), including information on crayfish species and the country in which the study was conducted (see Online Resource 1 for full details of the 35 papers included)

\begin{tabular}{llc}
\hline Species & Country of study & $\begin{array}{l}\text { Number of papers } \\
\text { (native + invasive) }\end{array}$ \\
\hline Astacus astacus & Sweden & $1(1+0)$ \\
Austropotamobius italicus & Spain & $1(1+0)$ \\
Austropotamobius torrentium & Austria & $1(1+0)$ \\
Cambarus bartoni & USA & $1(1+0)$ \\
Orconectes marchandi & USA & $1(1+0)$ \\
Orconectes propinquus & USA & $1(1+0)$ \\
Orconectes putnami & USA & $1(1+0)$ \\
Orconectes rusticus & USA & $5(2+3)$ \\
Orconectes virilis & USA & $3(2+1)$ \\
Procambarus clarkii & Italy, Spain, Portugal, USA & $6(0+6)$ \\
Pacifastacus leniusculus & Finland, Japan, Spain, Sweden, UK & $12(1+11)$ \\
Paranephrops planifrons & New Zealand & $1(1+0)$ \\
Paranephrops zealandicus & New Zealand & $3(3+0)$ \\
\hline
\end{tabular}

study duration and habitat type (whether the study was conducted in a river or a lake). Crayfish species was included as an additional covariate in the decomposition and primary productivity model because of greater sample size of the starting model. Models were fitted using generalized least squares (GLS) because several studies contributed multiple estimates of $d$ to the analysis: an error correlation structure accounted for potential non-independence of $d$ from the same studies (Pinheiro and Bates 2000). This meant that we were able to include a larger number of $d$ in the GLS model compared to when calculating weighted mean effect sizes, $d^{+}\left[n=\left(d^{+}\right.\right.$: GLS model $)$decomposition, 7:9; primary productivity, 14:19; invertebrate density, 13:15; invertebrate diversity, 8:10; invertebrate biomass, 5:6]. For laboratory studies crayfish endemic status was determined on the basis of whether or not the animals were native to the region from which they were harvested. Model fit was assessed using residual plots as recommended by Pinheiro and Bates (2000) and $d$ was square-root transformed to ensure adequate fit. Models were refined using step-wise deletions, manually removing the covariate with the highest $P$-value and re-running the model until only significant terms $(P<0.05)$ remained (Crawley 2007). Models were fitted using R statistical software [version 2.15.2 (R Development Core Team 2009)].

\section{Results}

The meta-analysis included studies from four continents on 12 crayfish species, eight exclusively in their native range, one exclusively in its invasive range and three within both their native and invasive ranges (Table 1). In general, crayfish densities used in these studies were similar to those observed in wild populations according to the 73 studies where both densities were estimated: study densities for three $d$ were lower than natural population densities, 57 were within the natural range (albeit often at the higher end of the natural range), and 13 were above the natural range. No evidence of publication bias amongst studies was observed.

Analysis of weighted mean effect sizes, $d^{+}$(Online Resource 3) revealed that both native and invasive crayfish significantly reduced invertebrate density and biomass, fish biomass and amphibian survival rate and significantly increased decomposition rates (Fig. 1). Invasive crayfish also significantly reduced plant biomass and invertebrate diversity and increased primary productivity (Fig. 1). All significant effects on ecosystem components were 'large', based on the conventional interpretation of the magnitude of $d$ [ $>0.8$ (Cohen 1969)]. The linear models of individual $d$ (Online Resource 4) showed that for decomposition and primary productivity $d$ was significantly greater for invasive than native species $\left(F_{1,25}=6.04, P=0.02\right)$ and for decomposition rate than primary productivity $\left(F_{1,25}=18.80, P=\leq 0.001\right) . d$ for these components were not significantly affected by crayfish density $\left(F_{1,22}=3.35\right.$, $P=0.08)$, species $\left(F_{7.8}=1.04, P=0.47\right)$, habitat type $\left(F_{1,7}=0.08, P=0.78\right)$ or study duration $\left(F_{1,15}=0.99\right.$, $P=0.34)$. For macro-invertebrate studies, there was no evidence that $d$ significantly differed between density, biomass or diversity $\left(F_{2,6}=0.02, P=0.98\right)$ or was affected by crayfish endemic status $\left(F_{1,8}=0.02, P=0.91\right)$, density $\left(F_{1,10}=3.54, P=0.09\right)$, habitat type $\left(F_{1,9}=0.21\right.$, $P=0.66)$ or study duration $\left(F_{1,13}=1.34, P=0.27\right)$.

\section{Discussion}

Our global meta-analysis shows that both native and invasive crayfish have significant and similar effects on 




Fig. 1 Weighted mean effect size $( \pm 95 \%$ confidence interval) of invasive (grey bars) and native (white bars) crayfish on a decomposition rate and $\mathbf{b}$ plant biomass, primary productivity, invertebrate density, biomass and diversity, fish biomass and refuge use and amphibian egg and larval survival. A negative mean effect size indicates a negative impact of crayfish on that organism/ecosystem process whereas the opposite is true for a positive effect size. Where confidence intervals do not intercept zero the result is significant $(P=0.05)$

ecosystem processes and the abundance/diversity of many aquatic taxa, reaffirming their perceived role as keystone species and ecosystem engineers (Creed 1994; Creed and Reed 2004). This suggests that crayfish, regardless of their endemic status, occupy similar functional roles within freshwater ecosystems.

Both native and invasive crayfish can affect plant and animal communities through predation (e.g. Charlebois and Lamberti 1996; Axelsson et al. 1997; Parkyn et al. 1997; Nyström et al. 2001; Dorn and Mittelbach 2004; Usio and Townsend 2004; McCarthy et al. 2006; Jackson et al. 2014; Moorhouse et al. 2014), demonstrated by their consistently strong negative effects on plant biomass, other macroinvertebrates, fish and amphibian eggs and larvae. Additionally, crayfish are likely to directly compete with other organisms for resources (Bubb et al. 2009). Indeed the current study provides some evidence of resource competition in finding that the refuge use of fish was significantly lower in the presence of invasive, but not native, crayfish. These direct effects of crayfish on individual ecosystem components may have indirect consequences on other aquatic organisms through trophic cascades (Nyström et al. 2001). For example, by reducing aquatic plant biomass, crayfish reduce the availability of refuges to macro-invertebrates and fish, which may indirectly benefit higher trophic levels (such as predatory fish, birds and otters) by increasing prey vulnerability. Despite evidence suggesting that predation on crayfish increased juvenile otter survival (Ruiz-Olmo et al. 2002) and that invasive red swamp crayfish were readily preyed upon by four species of mammalian carnivores and five species of ciconiiform birds (Correia 2001), there are currently too few data to properly assess the importance of crayfish as a dietary component for such predators. Our literature review did, however, suggest that crayfish can drive top-down trophic cascades. Various studies report that crayfish-induced reductions in invertebrate densities are associated with increases in primary productivity (e.g. Charlebois and Lamberti 1996; Nyström et al. 2001; Bobeldyk and Lamberti 2010). This would be expected as crayfish are known to prey heavily upon algivorous snails (Lodge et al. 1994; Parkyn et al. 1997; Nyström et al. 2001; Bjurström 2009), thereby releasing algae from grazing pressure and facilitating primary production. There are still too few examples to provide a quantitative test of the generality of this phenomenon, highlighting the need for empirical studies to include the effects of crayfish on multiple related ecosystem components.

Invasive crayfish significantly affected a larger number of the ecosystem components investigated than native species, suggesting that they may have greater impacts on freshwater ecosystems. Additionally, the magnitude of the mean effect size $\left(d^{+}\right)$of invasive crayfish was greater than that of native species on all ecosystem components for which their effects could be directly compared (i.e. everything apart from decomposition and primary productivity) except invertebrate density, which was greater for native crayfish. These results are consistent with the findings of Twardochleb et al. (2013) who also found that invasive crayfish caused greater reductions in the biomass and/ or growth rate of other invertebrates and fish, and greater increases in algal biomass than native crayfish. The relative impacts of invasive and native crayfish on decomposition rates, primary productivity, invertebrate diversity and amphibian egg and larval survival were not evaluated by Twardochleb et al. (2013). Greater impacts of invasive than native species are expected as populations tend to evolve to minimize the negative effects of interspecific interactions on individual fitness (Connell 1980; Futuyma and Slatkin 1983; Rummel and Roughgarden 1985; Shea and Chesson 2002), and community composition should adjust through 
ecological and evolutionary time to reflect interactions between constituent members (Diamond and Case 1986).

There are at least four non-exclusive explanations for invasive crayfish having greater ecological impacts than their native counterparts. First, crayfish species with strong effects may be more likely to be introduced and/or become invasive (Kolar and Lodge 2001; Marchetti et al. 2004; Ricciardi and Cohen 2007). Of the 21 studies on invasive crayfish within the current meta-analysis this only included four species. As there are few studies of these crayfish species in their native range, we were unable to assess whether they have consistently strong ecological impacts. Second, invasive crayfish may often be studied in communities that were previously crayfish free, which would confound the comparison of native-invasive effects with community history. Assessing this hypothesis was beyond the scope of the current study. Third, there may be a publication bias towards studies showing a detrimental impact of invasive species. Fourth, invasive crayfish may achieve higher population densities in recipient ecosystems (Parker et al. 2013), possibly owing to release from natural enemies (Torchin et al. 2003). Invasive crayfish are frequently observed at higher densities than natives. For example, invasive rusty crayfish (Orconectes rusticus) can reach densities 20 times higher than native species (Krueger and Waters 1983; Charlebois and Lamberti 1996). We found limited evidence that individual $d$ increased with crayfish density $(P=0.08$ for decomposition/primary productivity model and $P=0.09$ for the invertebrate model), but the sample sizes were modest ( $n=26$ and $n=23$, respectively). Therefore, from our data, it is unclear how important crayfish density is in determining the impact of crayfish on aquatic ecosystems.

$d$ for decomposition and primary productivity varied with crayfish endemic status, with the effect of invasive crayfish being greater than that of natives. This suggests that the impacts of crayfish on these ecosystem processes are variable and highlights that the endemic status of crayfish should be considered when trying to predict this effect. On the other hand the impact of crayfish on other ecosystem components may be more predictable; in the macro-invertebrate model, $d$ did not differ between invertebrate density, biomass and diversity, nor between native and invasive crayfish. However, investigating the impacts of crayfish on other invertebrates is complicated by the fact that such taxa may be differentially affected by crayfish (Usio and Townsend 2000; Twardochleb et al. 2013). Crayfish preferentially prey on large soft-bodied invertebrates, such as gastropods (Wilson et al. 2004; Bjurström 2009) but are ineffective predators of highly mobile invertebrate grazers, such as mayflies (Bjurström 2009). Therefore the impacts of crayfish on other invertebrates will vary largely depending on the species composition of the affected community, potentially confounding our comparisons between native and invasive crayfish for these variables. Regardless, our findings imply that translocating native crayfish for conservation purposes could have impacts upon some taxa or ecosystem processes that are of similar magnitude to those of invasive crayfish.

A second important conclusion from this study is the weakness of many aspects of the evidence base for quantifying the effects of native and invasive crayfish. There is a relative paucity of studies quantifying the effects of native and invasive crayfish in a way that can be synthesised, with some studies reporting only the results of statistical tests, excluding treatment group means and/or measures of variability that are essential for meta-analysis. For the meta-analysis, only 44 (35 of which were used in the final meta-analysis) out of 132 papers reviewed reported the data necessary for inclusion and these were unevenly distributed across taxa and ecosystem processes (Table 1). Within the included studies there is a lack of field experiments and/or observations for certain taxa, in particular amphibians. The value of laboratory studies on interactions between crayfish and these organisms is questionable because in most cases an alternative source of prey is not provided and the ability of the organism to escape crayfish predation is spatially restricted. Concerning the difference between native and invasive crayfish, there are comparatively few studies on the impacts of crayfish in their native ranges, and very few examples of individual crayfish species being investigated in both their native and invasive ranges. These deficits in the empirical evidence emphasise the need for papers to report basic statistics (including control and treatment group means, SDs and replicate numbers), and highlight the requirement for further study of native crayfish and ecosystem components, which are currently under-represented. Studies of individual crayfish species in both their native and invasive ranges are also required to clarify how the impacts of crayfish differ depending upon their native/ invasive status. Despite these caveats our results reveal that both native and invasive crayfish have strong ecosystemaltering effects, which vary in magnitude across ecosystem components.

\section{Conclusions and management implications}

Managing and preventing the impacts of invasive species requires the ability to assess the risks associated with current and future biological invasions. Leung et al. (2012) recently proposed a unified quantitative invasive species assessment framework which considers transport, establishment, abundance, spread and impact (TEASI), and meta-analyses like that presented here offer a promising approach for quantifying risk. For most existing and future invasive species, there will not be sufficient species and community-specific empirical data to inform case-specific 
decision-making. Meta-analysis can provide broadly applicable quantitative generalisations on the invasion biology of priority taxa.

Once invasive species become established, they are often difficult to eradicate. Combined with the threats of habitat fragmentation and climate change, protecting vulnerable native species may require managed relocations (Olden et al. 2010). Conceptually, such relocations are similar to biological invasions (Shea and Chesson 2002). There is thus legitimate concern that relocating native species may have unintended detrimental consequences on recipient ecosystems (Olden et al. 2010). Our results justify this concern; native crayfish had significant and large effects on numerous ecosystem components that were sometimes larger than those of invasive species. Overall, our findings suggest that the predicted conservation benefits associated with relocating a native species need to be weighed against the potential negative effects on the recipient ecosystem (Olden et al. 2010).

Ultimately, the findings of the current study will contribute to the conservation of freshwater biodiversity as they quantify the ecosystem-wide impacts of crayfish and so reinforce the need to develop efficient control mechanisms for invasive crayfish and strictly regulate translocations of native crayfish. By evaluating the general impacts of native and invasive crayfish on freshwater ecosystems this study provides a method of predicting the effects of new crayfish translocations and invasions. Our results help identify priorities for future research, underscore the range of factors that need to be considered when managing native and invasive crayfish, and highlight the potential contribution of meta-analyses in conserving global biodiversity.

Acknowledgments We thank Dr M. J. Vander Zanden and C. L. Hein for providing access to data from their meta-analysis manuscript (McCarthy et al. 2006). J. J. was funded by Natural Resources Wales and Cardiff University.

Conflict of interest The authors declare that they have no conflict of interest.

\section{References}

Axelsson E, Nyström P, Brönmark C (1997) Crayfish predation on amphibian eggs and larvae. Amphib-Reptil 18:217-228. doi:10. $1163 / 156853897 \times 00107$

Bjurström L (2009) Impacts of the non-native signal crayfish on littoral benthic invertebrate communities in Lake Päijänne. MSc thesis, University of Jyväskylä, Finland

Bobeldyk AM, Lamberti GA (2010) Stream food web responses to a large omnivorousinvader, Orconectes rusticus (Decapoda, Cambaridae). Crustaceana 83:641-657. doi:10.1163/0011216 10X491031

Bubb DH, Thom TJ, Lucas MC (2006) Movement, dispersal and refuge use of co-occurring introduced and native crayfish. Freshwater Biol 51:1359-1368. doi:10.1111/j.1365-2427.2006.01578.x
Bubb DH, Oliver OJ, Gooderham AC, Lucas MC (2009) Relative impacts of native and non-native crayfish on shelter use by an indigenous benthic fish. Aquat Conserv Mar Freshwater Ecosyst 19:448-455. doi:10.1002/aqc.1001

Charlebois PM, Lamberti GA (1996) Invading crayfish in a Michigan stream: direct and indirect effects on periphyton and macroinvertebrates. J N Am Benthol Soc 15:551-563

Clavero M, García-Berthou E (2005) Invasive species are a leading cause of animal extinctions. Trends Ecol Evol 20:110. doi:10.1016/j.tree.2005.01.003

Cohen J (1969) Statistical power analysis for the behavioural sciences. Academic Press, San Diego

Connell JH (1980) Diversity and the coevolution of competitors, or the ghost of competition past. Oikos 35:131-138. doi:10.2307/3544421

Correia AM (2001) Seasonal and interspecific evaluation of predation by mammals and birds on the introduced red swamp crayfish Procambarus clarkii (Crustacea, Cambaridae) in a freshwater marsh (Portugal). J Zool 255:533-541. doi:10.1017/ S0952836901001625

Crawley MJ (2007) The R book. Wiley, England

Creed RP (1994) Direct and indirect effects of crayfish grazing in a stream community. Ecology 75:2091-2103. doi:10.2307/1941613

Creed RP, Reed JM (2004) Ecosystem engineering by crayfish in a headwater stream community. J N Am Benthol Soc 23:224-236. doi:10.1899/0887-3593(2004)023\%3c0224:EEBCIA\%3e2.0.CO;2

Diamond JM, Case TJ (1986) Community ecology. Harper \& Row, New York

Didham RK, Tylianakis JM, Hutchison MA, Ewers RM, Gemmell NJ (2005) Are invasive species the drivers of ecological change? Trends Ecol Evol 20:470-474. doi:10.1016/j.tree.2005.07.006

Dorn NJ, Mittelbach GG (2004) Effect of a native crayfish (Orconectes virilis) on the reproductive success and nesting behaviour of sunfish (Lepomis spp.). Can J Fish and Aquat Sci 61:2135-2143. doi:10.1139/F04-158

Dudgeon D et al (2006) Freshwater biodiversity: importance, threats, status and conservation challenges. Biol Rev 81:163-182. doi:10.1017/S1464793105006950

Futuyma DJ, Slatkin M (1983) Introduction. In: Futuyma DJ, Slatkin M (eds) Coevolution. Sinauer, Sunderland, pp 4-8

Gherardi F (2010) Invasive crayfish and freshwater fishes of the world. Rev Sci Tech (Int Off Epizoot) 29:241-254

Gurevitch J, Hedges LV (2001) Meta-analysis: combining the results of independent experiments. In: Scheiner SM, Gurevitch J (eds) Design and analysis of ecological experiments. Oxford University Press, New York, pp 347-369

Gurevitch J, Padilla DK (2004) Are invasive species a major cause of extinctions? Trends Ecol Evol 19:470-474. doi:10.1016/j. tree.2004.07.005

Haddaway NR, Mortimer RJG, Christmas M, Grahame JWJ, Dunn AM (2012) Morphological diversity and phenotypic plasticity in the threatened British white-clawed crayfish (Austropotamobius pallipes). Aquat Conserv Mar Freshwater Ecosyst 22:220-231. doi:10.1371/journal.pone.0032229

Jackson MC, Jones TA, Milligan M, Sheath D, Taylor J, Ellis A, England J, Grey J (2014) Niche differentiation among invasive crayfish and their impact on ecosystem structure and functioning. Freshwater Biol 59:1123-1135. doi:10.1111/fwb.12333

Kolar CS, Lodge DM (2001) Progress in invasion biology: predicting invaders. Trends Ecol Evol 16:199-204. doi:10.1016/ S0169-5347(01)02101-2

Krueger CA, Waters TF (1983) Annual production of macroinvertebrates in 3 streams of different water quality. Ecology 64:840 850. doi: $10.2307 / 1937207$

Leung B et al (2012) TEASIng apart alien species risk assessments: a framework for best practices. Ecol Lett 15:1475-1493. doi:10.1111/ele.12003 
Lodge DM, Kershner MW, Aloi JE, Covich AP (1994) Effects of an omnivorous crayfish (Orconectes rusticus) on a freshwater littoral food web. Ecology 75:1265-1281. doi:10.2307/1937452

Marchetti MP, Moyle PB, Levine R (2004) Invasive species profiling? Exploring the characteristics of non-native fishes across invasion stages in California. Freshwater Biol 49:646-661. doi:10.1111/j.1365-2427.2004.01202.x

McCarthy JM, Hein CL, Olden JD, Vander Zanden MJ (2006) Coupling long-term studies with meta-analysis to investigate impacts of non-native crayfish on zoobenthic communities. Freshwater Biol 51:224-235. doi:10.1111/j.1365-2427.2005.01485.x

Moorhouse TP, Poole AE, Evans LC, Bradley DC, Macdonald DW (2014) Intensive removal of signal crayfish (Pacifastacus leniusculus) from rivers increases numbers and taxon richness of macroinvertebrate species. Ecol Evol 4:494-504. doi:10.1002/ ece 3.903

Nyström P, Svensson O, Lardner B, Brönmark C, Granéli W (2001) The influence of multiple introduced predators on a littoral pond community. Ecology 82:1023-1039. doi:10.1890/0012-9658 (2001)082[1023:TIOMIP]2.0.CO;2

Olden JD, McCarthy JM, Maxted JT, Fetzer WW, Vander Zanden MJ (2006) The rapid spread of rusty crayfish (Orconectes rusticus) with observations on native crayfish declines in Wisconsin (U.S.A.) over the past 130 years. Biol Invasions 8:1621-1628. doi:10.1007/s10530-005-7854-2

Olden JD, Kennard MJ, Lawler JJ, Leroy Poff N (2010) Challenges and opportunities in implementing managed relocation for conservation of freshwater species. Conserv Biol 25:40-47. doi:10.1111/j.1523-1739.2010.01557.x

Parker JD et al (2013) Do invasive species perform better in their new ranges? Ecology 94:985-994. doi:10.1890/12-1810.1

Parkyn SM, Rabeni CF, Collier KJ (1997) Effects of crayfish (Paranephrops planiforms: parastacidae) on in-stream processes and benthic faunas: a density manipulation experiment. NZ J Mar Freshwat Res 31:685-692. doi:10.1080/00288330.1997.9516798

Pinheiro JC, Bates DM (2000) Mixed-effects models in S and S-PLUS. Springer, New York

R Development Core Team (2009) R: a language and environment for statistical computing. R Foundation for Statistical Computing, Vienna. ISBN 3-900051-07-0. http://www.R-project.org

Ricciardi A, Cohen J (2007) The invasiveness of an introduced species does not predict its impact. Biol Invasions 9:309-315. doi:10.1007/s10530-006-9034-4
Ruiz-Olmo J, Olmo-Vidal JM, Manás S, Batet A (2002) The influence of resource seasonality on the breeding pattern of the Eurasian otter (Lutra lutra) in Mediterranean habitats. Can J Zool 80:2178-2189. doi:10.1139/z02-186

Rummel JD, Roughgarden J (1985) A theory of faunal buildup for competition communities. Evolution 39:1009-1033

Shea K, Chesson P (2002) Community ecology theory as a framework for biological invasions. Trends Ecol Evol 17:170-176. doi:10.1016/S0169-5347(02)02495-3

Sibley PJ, Brickland JH, Bywater JA (2002) Monitoring the distribution of crayfish in England and Wales. Bull Fr Pêche Piscicult 367:833-844. doi:10.1051/kmae:2002071

Stenroth P, Nyström P (2003) Invasive crayfish in a brown water stream: effects on juvenile trout, invertebrates and algae. Freshwater Biol 48:466-475. doi:10.1046/j.1365-2427.2003.01020.x

Strayer DL (2010) Alien species in fresh waters: ecological effects, with interactions with other stressors, and prospects for the future. Freshwater Biol 55:152-174. doi:10.1111/j.1365-2427.2009.02380.x

Strayer DL, Dudgeon D (2010) Freshwater biodiversity conservation: recent progress and future challenges. J N Am Benthol Soci 29:344-358. doi:10.1899/08-171.1

Torchin ME, Lafferty KD, Dobson AP, McKenzie VJ, Kuris AM (2003) Introduced species and their missing parasites. Nature 421:628-630. doi:10.1038/nature01346

Twardochleb LA, Olden JD, Larson EL (2013) A global meta-analysis of the ecological impacts of nonnative crayfish. Freshwater Sci 32:1367-1382. doi:10.1899/12-203.1

Unestam T, Weiss DW (1970) The host-parasite relationship between freshwater crayfish and the crayfish disease fungus Aphanomyces astaci: response to infection by a susceptible and a resistant species. J Gen Microbiol 60:77-90

Usio N, Townsend CR (2000) Distribution of the New Zealand crayfish Paranephrops zealandicus in relation to stream physio-chemistry, predatory fish, and invertebrate prey. N Z J Mar Freshwater Res 34:557-567. doi:10.1080/00288330.2000.9516957

Usio N, Townsend CR (2004) Roles of crayfish: consequences of predation and bioturbation for stream invertebrates. Ecology 85:807-822. doi:10.1890/02-0618

Wilson KA, Magnuson JJ, Lodge DM, Hill AM, Kratz TK, Perry WL, Willis TV (2004) A long-term rusty crayfish (Orconectes rusticus) invasion: dispersal patterns and community change in a north temperate lake. Can J Fish Aquat Sci 65:2255-2266. doi:10.1139/F04-170 